special reference to the question of storage. Full details are given of the experimental methods employed. Taking cultures of roo cubic centimetres of water as the final guide, it appears that, starting with an initial number of typhoid bacilli varying from 40 per c.c. to $8,000,000$ per c.c. in the infected water, the typhoid bacillus could not be recovered from 100 c.c. of the water in any of the eighteen experiments after nine weeks, i.e. in this period the organism had died out so far as experiment could ascertain, and in sixteen out of the eighteen experiments the organism had died out in eight weeks. If, therefore, the water before distribution to the consumer could be stored for an adequatc period, it would seem that the risk of conveyance of typhoid, supposing the water were infected, would be practically eliminated.

At present the Water Board's existing storage reservoirs are capable of holding in the aggregate 8883.7 million gallons, which is forty times the average daily supply of 219 million gallons, and powers have been obtained for the construction of storage reservoirs for another 6000 million gallons. When these are completed, the storage capacity would be adequate for the storage of the water for the eight or nine weeks necessary to eliminate the typhoid bacillus. Even in existing circumstances the conditions are by no means unsatisfactory. Unfortunately, however, the storage capacity at the different works is very unequal, and some have to take their water after only a limited period of storage. If the different reservoirs could be connected, and the supplies so " pooled," a better condition of things would result. Adequate storage of water also presents advantages of a general character, apart from the elimination of typhoid, e.g. subsidence of particulate matter which tends to block the filter-beds, reduction in the total bacterial content, \&c.

R. T. H.

\section{SOME RESULTS OF THE NORWEGIAN} HERRING INVESTIGATIONS.

"UNSERE Heringsstämme und ihre Wanderungen" is the title of a paper written for the Bergens Muscum Aarbog, I908, by Hjalmar Broch, dealing with some of the results of the Norwegian investigations into the herring fisheries. Extensive and detailed observations made by the Michael Sars, the Norwegian vessel for the international investigations, supplemented by information from other vessels, have yielded some valuable and interesting information as to this fish. One of the chief objects in view was to distinguish clearly the different races or varieties of herrings that are to be found in the North Sea, for it has of late been becoming more and more evident that each race of herring must be studied by itself, the characteristics and the direction and extent of the wanderings of the different shoals being very different. Following the method used by Heincke to accomplish this object, Broch has made a series of biometrical observations on numerous fish, and so determined their differences of structure, and these, accompanied by observations on sex, maturity, and fatness, have added considerably to our previous knowledge of the subject. Tables of the measurements are given, and the differences between the corresponding average measures on fish from different races, with their probable errors, are printed in the text, so that we are able at a glance to estimate the real significance of these differences. The inclusion of these in this form is of real value. For example, the differences between the averages of most races are considerably greater than their probabie differences, but there is no conclusive proof as yet whether or not the varieties known as spring and large herring are really of the same race.

The following kinds of herring and their characteristics are now well known:-

(I) The Dogger Bank herring in the central North Sca.

(2) The Bohusläns herring in the Skager Rak.

(3) The Shetland herring in the northerly and westerly parts of the North Sea.

(4) The Norwegian spring and large herring along the Norwegian west coast and the north-easterly part of the North Sea.
(5) The Beitstad Fiord herring in Trondhjems Fiord.

There is a short section on the age investigations, which are as yet not advanced enough to give many results. Age is determined by means of the annual rings in the herring scales. An examination of plate ii. shows that the length of a herring is not by any means a simple runction of its age, the growth rate being very different for the several kinds. The Beitstad Fiord herring, which is supposed to spend its whole life within the area of the fiord, is found to grow much more slowly than those races which frequent the open sea. In its fifth year it seldom exceeds a length of $22 \mathrm{~cm}$., whilst the herrings of the Norwegian seas may become 24 or $25 \mathrm{~cm}$. even in their second year.

The distribution of the various shoals and their movements at different times of the year have been studied. For instance, the spawning-places of the spring and large herring are found along the Norwegian coasts from Trondhjems Fiord to Risør, and the shoals gather here in early spring. The spent herrings then move into the open sea, and later in June they appear on the North Sea slopes. In autumn, I905, they were discovered on the coastal banks between Stadt and Lofoten, whence in December they moved in a southerly direction towards the spawning-places along the coast.

The value of these investigations is not for the man of science alone; they are of great importance to the practical fisherman, who, knowing exactly when and where the various shoals spawn, is able to catch the herring when they are prime and avoid them in their spent condition. Many interesting questions, such as the relation of the herring migrations to the distribution of plankton, yet remain to be solved, and these must be the object of further investigations.

R. M. L.

\section{ARCHAEOLOGICAL RESEARCH IN INDIA.}

A WRITER who has enjoyed unusually favourable opportunities of examining the conditions under which archæological research in India is being conducted has recently contributed to the Times a series of reports of his observations. Archæology in India is now at last, after a period of vandalism and neglect, being conducted on business and scientific principles. For this we are indebted to Lord Curzon.

The first serious attempt to collect information dates from the appointment, in 1862 , of General Cunningham as Director of Archæology. Owing to the wide extent of the sphere of operations and the difficulty of securing the services of qualified assistants, the result was far from satisfactory. A long series of reports was issued, which, though they contain some valuable material, are illarranged and overloaded with useless matter. Besides this, under the régime of General Cunningham the work of conservation of existing buildings formed no part of the proceedings undertaken by the Government of India. After the retirement of General Cunningham little progress was made until, under Lord Curzon's scheme, in Igor the post of Director was conferred upon Mr. J. H. Marshall, who, though without any Indian experience, had been trained in the Cambridge School of Greek Archæology. Since his appointment the work of conservation has gone on side by side with that of exploration, and important buildings like the Taj Mahal at Agra and the palaces at Fatehpur-Sikri have been judiciously restored. The most noteworthy excavations now in progress are those at the Buddhist monastery at Sarnath, near Benares, the buried city of Sravasti in northern Oudh, and the Græco-Buddhist remains in the neighbourhood of Peshawar. On the results of these excavations excellent periodical reports have been issued.

It is hardly realised what a wealth of archæological material still remains to be explored. Kapilavastu, the birthplace of Buddha, which lies just within the Nepalese Terai ; Pataliputra, the Maurya capital, in the neighbourhood of the modern Patna; and numerous sites of the first importance in the Punjab and the United Provinces of Agra and Oudh, such as Taxila, near Rawalpindi, still await exploration. Research at many of these sites is certain to unearth inscriptions and sculptures which will 
serve to fill up many a gap in the early history of the country. The main hindrances to progress are at present:- first, the exclusiveness of both Hindus and Mohammedans, who object to the examination of buildings which are still used for worship; secondly, the fact that many important ancient buildings are situated within the territories of native States, where it has up to the present been impossible to arrange satisfactory schemes for conservation and excavation. In spite of these drawbacks, archæological research in India has now been placed upon a sound footing, and in the immediate future a large amount of fresh material, in the shape of sculptures and inscriptions, will be at the disposal of students.

\section{ON ICE AND ITS NATURAI, HISTORY}

\section{$\mathrm{D}^{\mathrm{U}}$}

URING the Antarctic cruise of the Challenger in the chemical and physical properties of sea ice. The melting temperature of the ice varied with the samples, but it was always below $\mathrm{o}^{\circ} \mathrm{C}$., and it was found impossible by any means to produce pure water by melting it. These two facts were for me convincing evidence, at that date, that the salt was present in the ice in the solid state, and that, consequently, the crystalline body, formed by freezing seawater and similar saline solutions, was not pure ice.

About nine years later Dr. Otto Petterssen, having his attention directed in a similar way to the same subject. arrived at the same conclusion. His observations and their discussion are embodicd in a remarkable paper on the properties of ice and water (Publications of the Vega Expedition, 1883). In the careful study which I made of this work the following passage arrested my attention:"A thermometer immersed in a mixture of snow and sea water, which is constantly stirred, indicates $-1^{\circ} .8 \mathrm{C}$."

If this statement was exact, it was clear that the evidence furnished by the melting temperature of the sea ice was not entitled to the weight which I attached to it, and that the conclusion at which we had independently arrived was open to doubt. On repeating the experiment, I was able to confirm Petterssen's statement. I then proceeded to investigate the subject in detail. The principle which guided the investigation was the following :- if the crystalline body, which is formed when a nonsaturated saline solution is partially frozen, is pure ice, then pure ice of independent origin, such as snow, must, when mixed with the same saline solution, and heat is supplied, melt at the same temperature when the concentration is the same.

This was found to be the case; and the result of the research was definitively to establish, on experimental evidence, the validity of the principle that, when a nonsaturated saline solution is partially frozen, the crystals which are formed are pure ice; and, by consequence, that the salt from which it is, in practice, impossible to free them, belongs to the adhering brine. ${ }^{2}$

It was not until after this had been established, in 1887 , that it became legitimate to say "the freezing point of water is lowered by the presence of salt dissolved in it," instead of saying "the freezing point of a saline solution is so much lower than that of pure water." The former of these statements expresses the fundamental principle of cryometric chemistry.

Shortly, I define the freezing and melting temperature of a substance to be the temperature at which it as a solid passes into itself as a liquid, and as a liquid passes into itself as a solid. In terms of this definition the freezing and melting temperature of the substance $\mathrm{H}_{2} \mathrm{O}$ is $0^{\circ} \mathrm{C}$. In order to represent the temperature at which ice melts, this definition requires a double qualification. At constant pressure the temperature at which ice melts 1 Abridged from a discourse delivered at the Royal Institution on Friday evening, May 8, by J. Y. Buchanan, F.R.S.

2 The results of the research which I began in the year $x 886$ were communicated to the Royal Society of Edinburgh in a paper "On Ice and Brines," which was read on March 2x, 1887 , and was published in the Proceedings of the Society, vol. xiv., pp. r29-r49. A full account of it was also published in NATURE, 1887, vol. xxxv, p. 608 , and vol. xxxvi., p. 9 . gation of the substance $\mathrm{H}_{2} \mathrm{O}$ at temperatures below its normal freezing and melting point and above its normal boiling and condensing point was passed, in review in my chemical and physical notes in the "Antarctic Manual,"
2gor, pp. 73-ro8. depends on the nature of the medium in which it melts and if the nature of the medium be constant, the temperature at which ice melts depends on the pressure. Of the two modifying agencies, the influence of the medium preponderates in-nature. Indeed, inasmuch as perfectly pure water is rarely, if ever, met with, it is probable that, in nature, ice never melts and water never freezes exactly at $0^{\circ} \mathrm{C}$.

The principle that the temperature at which ice melts depends on the nature of the medium in which it melts is the key to the natural history of ice, and it forms the theme or text of this discourse. It at once brings into order the anomalies frequently observed in the experimental determination of many of the physical constants of ice, such as its coefficient of thermal expansion, its specific and its latent heat. When the ice or the water in which it is immersed contains any impurity, the temperacur $\ldots$...isich the ice begins to melt is below $0^{\circ} \mathrm{C}$., and the substance under examination, which is taken for pure solid ice, is in reality a mixture of ice and impure water.

In discussing this subject, chloride of sodium is taken as the representative impurity, because it is the most widely disseminated ingredient of natural waters. It has also been more thoroughly studied than other salts in its behaviour to ice, water, and steam. In discussing the influence which this salt exercises over the apparent physical properties of ice a constant quantity of it is considered, and the quantity of ice on which it acts is varied. The constant quantity of the salt is $\mathrm{I}_{5}$ ro5 grams, which contain 0.9167 gram of chlorine. The specific gravity of pure ice is taken as 0.9167 referred to that of water at the same temperature as unity.

It will be recognised that when rooo c.c. of ice containing 1.5105 grams $\mathrm{NaCl}$ are melted, they furnish a water which contains chlorine in the proportion of $\mathrm{I}: \mathrm{I00O}$ by weight. The coefficient of cubic expansion by heat of pure ice is taken as 0.00016 , and it is assumed to be constant at the temperatures under consideration. The volume occupied by the 1.5105 grams $\mathrm{NaCl}$ is disregarded. The cryohydric temperature of $\mathrm{NaCl}$ solution is taken as $-2 \mathrm{I}^{\circ} .7^{2} \mathrm{C}$., and its cryohydric concentration as 29.97 grams salt to Ioo grams water.

Using these constants, we will apply the principle to the calculation of the apparent variations of volume of a block of ice the volume of which at $0^{\circ} \mathrm{C}$. is 1000 c.c. It contains diffused through it $\mathrm{I}_{5} 5_{105}$ grams $\mathrm{NaCl}$, which we assume to be provisionally in the inert state, in which it is deprived of the power to induce the melting of ice at temperatures between $0^{\circ} \mathrm{C}$. and $-21^{\circ} \cdot 7^{2} \mathrm{C}$. Let the temperature of the block containing the inert $\mathrm{NaCl}$ be reduced to $-23^{\circ} \mathrm{C}$.; its volume will be reduced to 996.320 c.c., and as the temperature is below the cryohydric temperature, the salt is by nature inert; at such temperatures ice and common salt are indifferent to each other. Let the temperature of the block of ice be now raised to $-22^{\circ}$; the salt remains inert, and the volume of the ice increases to 996.48 c.c. If the temperature is further increased to $-2 \mathrm{I}^{\circ} \cdot 72 \mathrm{I}$, the $\mathrm{NaCl}$ will still remain inert, and the volume of the ice will become 996.525 c.c.

If the heating is continued the temperature rises exactiy to the cryohydric point, $-2 \mathrm{I}^{\circ} \cdot 72$, at which temperature the indifference of chloride of sodium to ice ceases, and induced melting at that temperature takes place. It will then be observed that the temperature remains constant for a time, while the volume of the block diminishes. When the temperature begins to rise, the volume of ice melted will be 5.498 c.c. As this produces 5.040 c.c. water, the diminution of volume is $0.45^{8}$ c.c., and the apparent volume of the block is 996.067 c.c.

Let us now go back to the initial state, in which we have the block of rooo c.c. ice, containing 1.5105 grams inert $\mathrm{NaCl}$ diffused through it, at the temperature $0^{\circ} \mathrm{C}$. Let the temperature be reduced to $-2 \mathrm{r}^{\circ} \mathrm{C}$., the ice remaining inert. The volume of the ice will then be 996.64 c.c. Let the $\mathrm{NaCl}$ recover its activity, it will melt 5.629 c.c. ice, producing 5.I6o c.c. water under a contraction of 0.469 c.c., so that the apparent volume of the ice at $-2 \mathrm{I}^{\circ} \mathrm{C}$. is $996 \cdot 64-0.469=996 \cdot \mathrm{I} 7 \mathrm{I}$ c.c. Proceeding by steps in this way, we obtain, for different temperatures $t$, the volume of the ice containing inert salt $V$, the volume of ice melted by the salt when its activity is 